\title{
Interactive Methods of Teaching the Humanities in Higher Education Institutions
}

\author{
Marchenko Nataliia, Vanovska Inna
}

\begin{abstract}
The article analyzes modern methods of interactive teaching of humanities in higher education institutions. A characteristic feature of interactive learning is the constant, active interaction of all participants in the educational process (teacher - student, teacher - students, students - students). It focuses on the fact that student-centered learning requires teachers to use the latest methods, providing the maximum connection of theoretical information with its practical application, the development of professional skills by directly solving cases and problematic situations. Characteristic of modern higher education is the development of critical thinking of students using such methods as "Fish bone", Bloom's daisy, Bloom's cube, Brainstorming, six hats of de Bono thinking and more. Interactive learning is based on a personal-activity approach that focuses on the use of both situational and nonsituational learning methods. Extremely important for professional activity and team work is the ability to express their own ideas and prove their viability. For this purpose, teachers of higher education institutions use such methods as debate, aquarium, PRES method, discussions, "Choose/change position", etc. The creative component of education is an integral part of professional development. With this in mind, the article analyzes such forms of student work as writing essays, syncveins, diamonds, portfolios, etc. Interactive learning methods motivate participants in the learning process to learn, stimulate their independent thinking and decision-making, develop imagination and cognitive interest. These methods can create an educational environment in which theory and practice are acquired simultaneously, contributing to critical and logical thinking, the formation of personality.
\end{abstract}

Keywords: interactive methods, educational process, professional knowledge, critical thinking, student-centrism.

\section{INTRODUCTION}

One of the main features of the development of modern higher education is the use of innovative technologies that promote the active acquisition of theoretical information by students and the development of practical skills that are necessary for the specialist to fulfill the tasks set by an employer. Currently, the main mission of a teacher is to build an educational process that is as close as possible to professional and life situations. The teacher systematically forms in students a creative approach to solving professional problems, critical and strategic thinking, the ability to work independently and in a team, the desire for self-education and self-improvement throughout life.

Revised Manuscript Received on August 13, 2020.

* Correspondence Author

Marchenko Nataliia*, Associate Professor, Department of Adult Education National Pedagogical Dragomanov University Kyiv, Ukraine. Email: n.marchenko@npu.edu.ua

Vanovska Inna, Associate Professor, Department of Leading Researcher of Linguistic Research and Development, Military Institute of Taras Shevchenko National University of Kyiv, Ukraine. E-mail: vanovskaya@ukr.net

(C) The Authors. Published by Blue Eyes Intelligence Engineering and Sciences Publication (BEIESP). This is an open access article under the CC BY-NC-ND license (http://creativecommons.org/licenses/by-nc-nd/4.0/)

Student-centered learning in higher education requires the use of effective teaching methods, where interactive ones are paramount. These methods arouse students' interest and motivation to learn, stimulate their independent thinking and decision-making, develop imagination and cognitive interest and more. We share the opinion of P. Freire, who argued that "a person achieves free personal development only as a result of equal dialogue, in which he has the right and opportunity to speak his word "about the world around and transform this world through critical perception of reality" [8]. That is why it is extremely important today to show the young generation in practice ways to solve those professional situations that they may face almost every day, or to prepare them for non-standard ones that will require the use of critical thinking and appropriate professional solutions.

Analysis of recent research and publications shows that the application of interactive methods of teaching the humanities in higher education was reviewed in the works of E. Batalshchikova, G. Krivchikov, L. Melnik, I. Lutsyk, Y. Semenchuk, T. Serdyuk, S. Sysoeva, O. Sichkaruk, H. Usmanaliev and others. Researchers focus only on certain aspects of the application of interactive teaching methods in higher education institutions, their classification and description. The purpose of our article is to analyze and describe modern methods of interactive teaching of humanities in higher education institutions, to illustrate the possibility of using interactive methods in teaching students.

\section{THEORETICAL BASIS OF THE RESEARCH}

"Interactive learning ("inter" - reciprocal, "act" - to perform an act) is a special form of organization of cognitive activity, involving the creation of comfortable learning conditions in which the student feels his success and intellectual capability" [7]. During the educational process, the teacher acts as a manager of organized knowledge acquisition by students, for whom information becomes a mean of acquiring professional skills and abilities. Thus, the purpose of interactive learning is "the creation by teacher of such learning conditions in which the student will discover, acquire and construct knowledge and his own competence in various spheres of life" [5, p.300].

A characteristic feature of interactive learning is the constant, active interaction of all participants in the educational process (teacher - student, teacher - students, students - students). Thus, a partnership is established, during which the analysis of complex professional situations and ways to solve it by one or another participant, who have the opportunity to be as close as possible to future professional activities. 
Interactive learning is based on a personal-activity approach that focuses on the use of both situational and nonsituational learning methods. The teacher, choosing one of these methods, organizes and coordinates the acquisition of new information, cooperation between students. Thus, "learning outcomes are achieved by mutual efforts of participants in the learning process, students take responsibility for learning outcomes" [2].

Quite popular today is the classification of interactive methods by O. Pometun and L. Pirozhenko [4], who grouped them by the purpose and forms of organization of the educational process on the methods of cooperative learning, collective group learning, situational modeling technology and discussion technology (Table- I). We will analyze the popular methods of interactive learning in higher education institutions.

Table- I: Classification of interactive learning methods (O. Pometun, L. Pirozhenko)

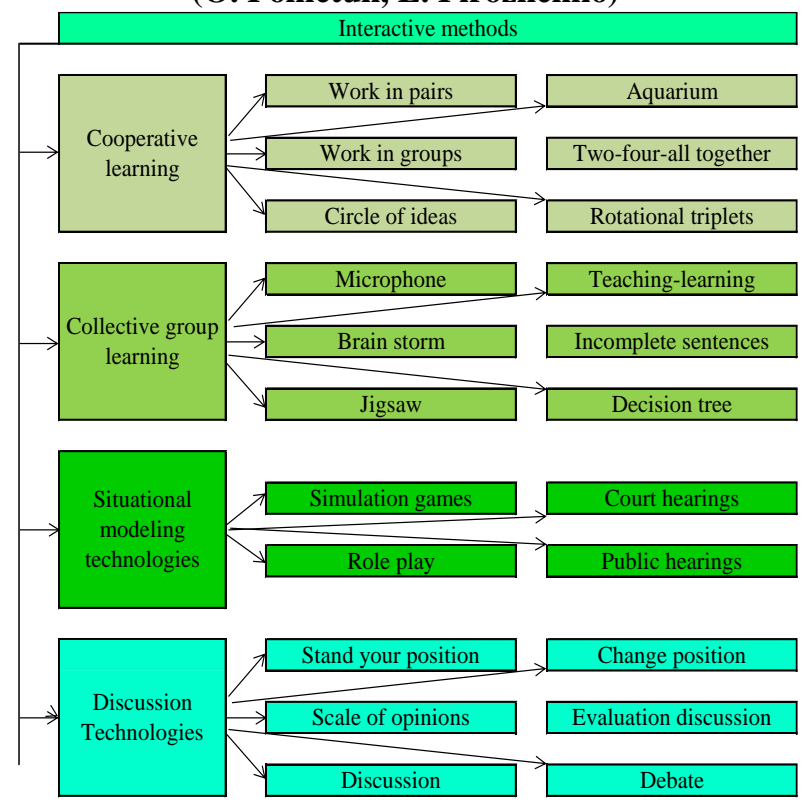

\section{RESEARCH RESULTS}

Tutorial is a form of work in higher education institutions, which is aimed at organizing, adjusting and controlling the independent work of students. The teacher interacts with the group or individually with the student by dividing the tasks and detailed instruction on their implementation.

The tutorial is characterized by high level of interactivity. Its main purpose is a deep familiarization of the students with the subject studied, discussion of creative projects (essays) during classes (twice a month) and the development of creative potential. This form of independent work allows students to learn how to think, for example, to synthesize different sources, formulate their own theses and prove them, anticipate criticism of their arguments and answer questions.

Tutorials foster the development of:

- basic skills of students (for example, identification and evaluation of relevant resources, confident oral or written communication, effective time management, critical selfassessment);

- ability to think and act like a professional;
- productive interaction of the student and the tutor during the solution of tasks, fostering his personal development during all segments of educational process.

The main strategies of an effective tutorial:

- planning - a clear identification of the main problems that need to be considered during the lesson, the early preparation of visual material and a few additional questions related to student projects;

- communication - creating an environment in which students actively participate in the discussion of the presented results of independent work - both of their own and colleagues;

- interaction - establishing an organic connection between the acquired knowledge on the subject and the results of independent work on the project, i.e. the development of practical professional skills;

- system of questions - support of constructive discussion, "brainstorming", etc.;

- constant work on the task - conducting briefings on the purpose and objectives of the task, deadlines, as well as assistance during their implementation;

- motivation, etc.

Thus, the tutorial allows you to create the most favorable environment for independent work of the student and the development of the personality of a professional who is confident, able to formulate his own opinion and present his work to colleagues.

One of the modern methods of interactive learning is "Fish bone". This chart, also named after its developer, Professor Ishikawa Kaoru, looks like a fish skeleton and aims to identify the significant causal links to the problem. The scheme consists of four blocks (Fig. 1): head (problem that needs analysis), tail (conclusions, generalizations), upper (concepts, causes of the problem) and lower (facts that reveal the causes) bones. The teacher, using the method of "Fish bone" during a lecture or practical lesson, is able to schematically depict the problem that underlies it along with students, as well as to make a brief analysis and express ideas for its solution in the process of filling the diagram. In this way, a fairly large layer of information can be easily memorized by the student and reproduced quickly.

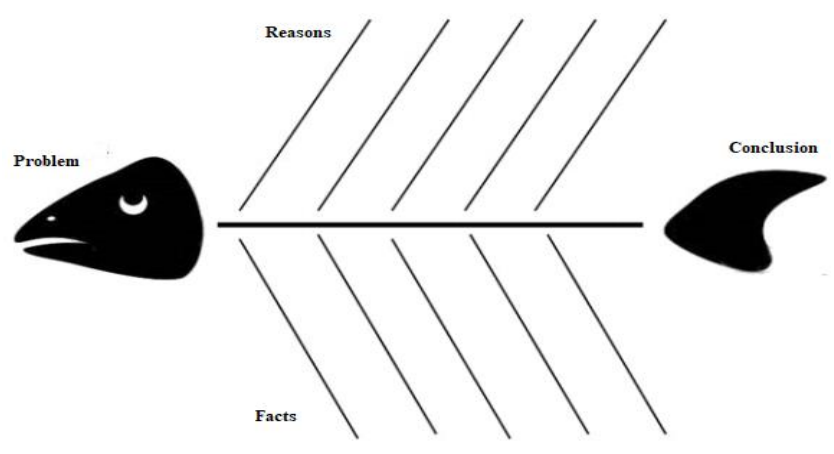

Fig. 1. Ishikawa diagram

For interactive learning, it is important to use the technology of critical thinking, which is to form an proactive, creative personality who is able to critically evaluate information and make appropriate decisions.

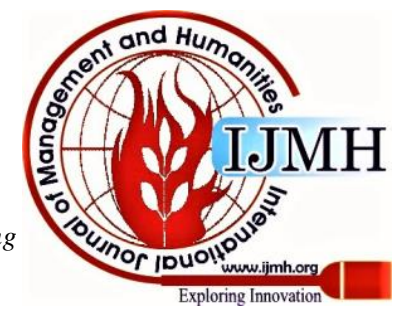


There are three phases of development of this technology: revocation - actualization of cognitive processes, understanding of the acquired content, comprehension (reflection). During the educational process in a higher education institution, we recommend using mental maps, Bloom's daisy, Bloom's cube, Brainstorming, six de Bono thinking hats.

In order to reduce the information load, develop attention skills, stimulate basic cognitive processes and the formation of stable intellectual skills, communication and intellectual competence, mental maps are used. They are based on the principle of cognitive visualization, i.e. visualization stimulates the intellectual process of acquiring knowledge.

"During the processing of information, a person uses both linguistic, symbolic and graphic sign systems, which represent this knowledge in a concise, compact form. At the same time, certain connections are built between the elements of knowledge, forming a unique scheme in human memory, the most convenient and effective for storage and further reproduction of information" [1, p. 21].

Mental maps can be used in lectures, practical or seminar classes, to study new material, its consolidation, generalization and structuring; during the processing of new material by students; in order to solve creative tasks, create presentations, develop projects, etc.

Drawing up students' own mental maps is one of the ways to identify gaps in their knowledge, a simulator for independent work with educational and reference literature, a means of developing intelligence, cognitive activity, structured thinking.

The use of mental maps in the higher educational process gives positive results: it improves the quality and intensity of learning, teaches to highlight the most important related theses in the huge layer of information.

Chamomile and Bloom's cube contains a range of questions that correspond to the topic of the lesson, update the knowledge and experience of students. The teacher can ask questions independently after the student has dropped a certain face of the cube or torn off a flower petal, or request the participants to formulate questions for their colleague. These techniques provide an opportunity to fully understand a phenomenon or a problem.

Brainstorming is a group method of solving a problem aimed at overcoming uncertainty: quite often people are afraid to express their own innovative ideas because they are afraid to get a skeptical assessment from colleagues or management. The method is based on two principles: "postponement of the verdict on the idea" and "quality is born from quantity". Two teams ("Generators" and "Analysts") express and analyze the new ideas for an hour. At the final stage, a list is created, which includes those ideas that are original, rational, creative and allowing to optimally solve the problem. Thus, this method is aimed at developing the ability to work in a group, confidently share their own ideas and adjust them according to the relevant advice of colleagues.

The case-study method remains quite productive and as close as possible to real life. The main purpose of this method is to model the professional situation (so-called "case"), its analysis, discussion and decision-making by students. Case-study combines teaching, educational and analytical activities. The student is placed in a situation where he needs to analyze the real situation, explore the essence of the problem, offer ideas for its solution and obligatory accept the only acceptable way out of the situation.

The case-study method "can be considered as a complex system in which other, simpler methods of cognition are integrated, including modeling, systems analysis, issues method, thought experiment, methods of description, classification, game methods" [6, p. 127].

The main requirements for the case-study method are:

- the case should contain the necessary information about the situation that students may face in professional life;

- the proposed situation should be complex enough, contain several alternative ways to solve the problem;

- the case should be adapted to the knowledge of students at this stage;

- the solution of the problem is directed by the teacher, etc.

In our opinion, this method is based on the "success situation", i.e. the student's ability to apply their own theoretical knowledge, critical thinking, creativity, rhetoric and psychological analysis, to be satisfied with the results, which is the driving force of motivation, promoting cognitive activity.

Discussion technology is a mandatory element of the modern higher education. It is extremely important for the of students' critical thinking development, determination of their stand and the ability to prove their own ideas using the acquired knowledge. These technologies include: the PRES method, debates, discussions, "Choose/change position", etc.

- The PRES method is used in higher education institutions to discuss issues with students. The teacher invites the participants of the educational process to formulate and express arguments on the existing problem and try to convince others. You can suggest a scheme by which students build their statements: "I believe that...", "... because...", "for example", "therefore".

- Discussion, as a method of interactive learning, is based on creative, collective, open and friendly cooperation of a group of students, aimed at resolving a controversial issue. This method promotes not only critical thinking, but also professional communication of students.

The teacher, having clearly defined the problem to be discussed, should outline a range of issues that can stimulate participants to conduct a discussion, control its conduct, make generalizations from time to time, create an atmosphere of mutual respect and democracy. There are many technologies for discussion, directly depending on its types:

- round table - discussion of ways to solve the problem by a group of students up to five people, followed by the announcement of their final idea to the audience;

- forum - a meeting of an expert group, discussing its ideas with the audience of students;

Published By:

Blue Eyes Intelligence Engineering \& Sciences Publication 


\section{Interactive Methods of Teaching the Humanities in Higher Education Institutions}

- symposium - speeches of several participants on a particular issue, accompanied by a number of questions from students;

- court hearing - imitation of a court hearing, requiring a clear division of roles and compliance with the rules of the court hearing;

- aquarium - discussion of the issue in a microgroup, during which the first group discusses (3-5 minutes), and the other only observes. After the announcement of the issue' solution, the exchange of roles takes place, which promotes pluralism of opinions. the issuw, public and personal activity;

- debate is the most difficult way to conduct a discussion, as it involves significant preparation of all participants and the sharpness of the discussion of the problem. 2-3 groups of students and judges take part in the debate. Each group must convince the students to accept their point. The debate consists of several stages:

1. Preparatory. Announcement of the topic and division of students into groups. They should elaborate on the proposed issue, form arguments and counter-arguments to convince the judges on the correctness of the opinion. The teacher names the time and outlines the procedure for the debate.

2. Conduct of the debate. The judges record the minutes, indicating of more convincing arguments of the teams, and select the winner.

\section{Summing up.}

One of the rules of debate is to formulate the problem in such a way that it would not be possible to answer yes or no. The topic of the debate should be relevant and arouse public interest. Team arguments should be based on knowledge, facts, not conjecture.

Thus, careful preparation and an official atmosphere in which the debate takes place arouses great interest of students, the desire to make the best possible use of their own knowledge and to defeat the opponents. In our opinion, systematic preparation for this form of training allows students to use not only the information obtained during classroom classes, but also to independently search for additional information and logically build speeches.

An effective method for activating the learning process, gaining knowledge and developing skills by students is to use such a simulation method of learning as a game. The use of game technology helps to increase the level of memorization of information, stimulates thinking and promotes creativity, requires concentration and accumulation of all efforts to solve the problem. The use of game methods in the study of humanities is relevant, because modeling the situation contributes to the development of knowledge, skills and abilities in practice, which gives students the opportunity to gain some experience in solving real problems.

The main functions of the game in the process of the discipline acquisition are:

- cognitive - obtaining the new information about the surrounding reality;

- training - application of knowledge in practice, development and consolidation of developed skills and abilities;

- communicative - helps to develop the ability to have a constructive business conversation using professional terminology;
- television talk show - imitation of public discussion of

- socialization - the development of the ability to work in a team, listen to the opinions of others;

- diagnostic - identifying the degree of information acquisition obtained from the course;

- entertaining - manifestation of interest and emotions.

Today, business game as a method of active learning, is very popular among teachers. Its characteristic features are a clear statement of goals and objectives, professional orientation, imitation, and so on.

The use of business games during training contributes to the solution of a significant number of educational tasks:

- generalization, consolidation and application of the acquired knowledge during the study;

- development of skills to prove one's own opinion, supporting it with legislative documents;

- socialization of the individual (ability to work in a team, organization of group interaction).

The business stage requires highly rigorous stage of preparation:

- the teacher must clearly outline the purpose, objectives and rules of the game;

- description of roles and functions of players;

- instructing student players.

The teacher, as an instructor-consultant, skillfully sets the situation of the professional game, leads it, manages the process of solving the problem, prevents conflicts.

At the end of the game it is necessary to discuss with students its results, ask the following questions:

- Did the players cope with their roles?

- Were there moments in the game in which you would have acted differently? If so, explain your statement.

Summarizing the game is a very important final stage, covering the analysis and evaluation of players, identifying errors, inaccuracies and gaps in the knowledge of participants, which will help eliminate them and avoid repetition during the possible solution of such a problem in real life.

Imitation methods develop the imagination, creativity and ingenuity of the individual. When modeling a situation, a person perceives it as real, and for this to the smallest detail reproduces in his head the parameters of a professional game, develops a strategy of behavior, predicts probable ways of events and chooses his way of solving the problem. Such individuals are able to respond quickly to unexpected questions or developments, make unusual decisions and be creative in solving problems.

Let's pay attention to individual forms of interactive learning in higher education institutions. These include: assembly of associative chains, shrubs, clusters; creation of interactive presentations; creation of diamonds and syncveins, portfolio, essay writing, etc.

The important forms of work in higher education institutions, contributing to the structuring of information are the formation of associative chains, bushes and clusters. The method of associative modeling is aimed at spontaneous memorization of information. 
Emphasis on the key concepts of the lecture further fosters its unobstructed reproduction and systematization of knowledge. Creating diamonds and syncveins allows to assess the qualities of a person, situation or the object. A syncvein is a blank verse that contains five lines (the name of a person or object, a description, an action, a feeling, a synonym for the title). Its compilation helps to understand and evaluate the advantages or disadvantages of the object of analysis. Diamond is a blank verse of seven lines, the first and last of which are opposite in meaning. This verse allows us to compare and distinguish the positive and negative aspects of the use of objects. Such a creative approach contributes to a clear outline of the advantages and disadvantages of the topic under analysis, and, consequently, a quick choice of what requires a situation. One of the methods of interactive learning is "portfolio", which is based on self-assessment and self-certification of the student. This method is aimed at self-analysis, selfimprovement, and, accordingly, the professional growth of the individual, which is very important in times of information and technological progress and increased employers' requirements tfor the employees. N. Perkhailo distinguishes three types of portfolio: demonstration (summarizes students' academic achievements, collects their best works); portfolio of professional growth (certifies the process of professional development of students); instrumental - provides clarity and accessibility of the student's presentation of the mastered material" [3, p. 325]. The main principles of this method include: learning' orientation on achieving specific results, creating an educational environment aimed at forming professional competencies, conducting project activities that promote constructive thinking, the ability to plan, conduct systematic research, present results, etc. Thus, the portfolio method is aimed at forming in future professionals the desire for continuous professional growth and development, increasing the value of such a person in the labor market. Essay writing is an important tool in the education of higher education institutions' students. Its writing requires significant theoretical training and elaboration of the necessary information. In the international educational practice, academic essays are required to enter a university, take international exams, or participate in grant programs. It is a kind of diagnostic tool for the creative component of the student's cognitive activity, his ability to analyze and interpret information, draw conclusions and argue his own assessment. One of the advantages of using this creative work in higher education institutions is the ability of the student to logically and clearly formulate his opinion, confidently use terminology, use quotes and apt examples to prove his views, shape his individual style and more. Academic writing develops cognitive and language skills, fosters knowledge consolidation, increases literacy and expands professional knowledge.

\section{CONCLUSION}

The use of interactive teaching methods in the process of studying the humanities diversifies the educational process, develops students' cognitive interests and team-working skills. These methods will create an educational environment in which theory and practice are acquired simultaneously, contributing to critical and logical thinking, the formation of personality. The article will be of interest for scholars-practitioners, actively using interactive teaching methods in teaching. The further research would be best directed to the analysis of the modern teaching methods, improving the educational process in the higher education.

\section{REFERENCES}

1. T. Koltunovich, O. Polishchuk, «The use of mental maps as a means of visualization in the teaching of social psychology». A young scientist. 2019. № 7.1. Pp. 19 - 27.

2. D. Ostapchuk, N. Myronchuk, «Interactive teaching methods in higher education». Modernization of higher education in Ukraine and abroad. Zhytomyr, 2014. - P. 140-143.

3. N. Perhailo, «The role of professional portfolio in the professional training and formation of students». Scientific notes of Ternopil National Pedagogical University named after Volodymyr Hnatyuk. Series: pedagogy. 2015. №2. Pp. 323-328.

4. O. Pometun, L. Pirozhenko, Modern lesson. Interactive learning technologies: Scientific method. tool. Kiev, 2004. - 136 p.

5. M. Radchenko, «Interactive learning technologies in the professional development of future professionals». Pedagogy of formation of creative personality in higher and general education schools. 2014 Issue. 34 (87). Pp. 299 - 306.

6. N. Terentieva, D. Nedashkivska, «The essence and structure of the case method: separate aspects». Taurian and Bulletin of Education. 2013. №1 (41). Pp. 123 - 129.

7. T. Turkot, Higher school pedagogy: A textbook for students of higher educational institutions. - К: Кондор, 2011. - 628 c.

8. P. Freire, Pedagogy of the oppressed. Lviv, 2003. 168 p.

\section{AUTHORS PROFILE}

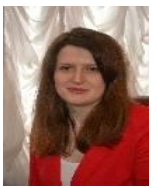

Marchenko Nataliia, Ph.D. in Pedagogy, Associate Professor at the Department of Adult Education National Pedagogical Dragomanov University. Sphere of interest: electronic resources in education, adult education, Ukrainian language teaching methods, innovative teaching methods.

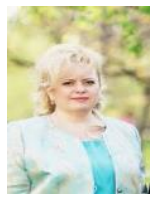

Inna Vanovska, $\mathrm{PhD}$ in History, Associate Professor Leading researcher Linguistic Research Boardt of the Military Institute of Taras Shevchenko National University of Kyiv. Sphere of scientific interest: modern communication, document science, communication systems. 